\title{
Medical Students' Readiness for Cutbacks in Health Care Expenditures of Alcohol-dependent Individuals
}

\author{
An Indicator for Stigmatization?
}

\author{
Hannah Hoffmann ${ }^{1}$, Julie Koschinowski ${ }^{1}$, Gallus Bischof ${ }^{1}$, Georg Schomerus², \\ Hans-Jürgen Rumpf ${ }^{1}$
}

Department of Psychiatry and Psychotherapy, University of Lübeck, Germany

Department of Psychiatry and Psychotherapy, University of Leipzig, Germany

\begin{abstract}
Background: Despite being affected by a severe disease with increased morbidity and mortality, alcohol-dependent individuals often experience stigmatizing situations in the health care system. This study aimed to investigate medical students' attitudes towards alcoholism and their readiness for cutbacks in health care expenditures for alcohol-dependent individuals. Methods: In total, 2253 students of all federal states in Germany took part in this study. Attitudes towards alcoholism, sociodemographic variables, and motives for studying medicine were assessed with an online questionnaire. Students' readiness for cutbacks in health care expenditures of alcohol-dependent individuals was measured in relation to the other diseases, including psychiatric conditions (e. g. depression, schizophrenia), potentiallystigmatized non-psychiatric disorders (e.g. AIDS), and potentially lifestyle-related acute (e.g. myocardial infarction) or chronic (e.g. diabetes) conditions. Data were analyzed with hierarchical logistic regression models. Results: Compared to other medical and mental diseases, alcoholism was by far the most frequently chosen condition with a potential for financial savings. In multivariate analyses, the preference for cutbacks was associated with the increased wish for social distance, high internal attribution of responsibility, low perceived severity and personal vulnerability, the absence of alcoholism in participants' social environment, and certain motives for studying medicine. Discussion: Since the majority of alcohol-dependent individuals avoid seeking addiction-specific help, physicians in primary care are often the only contact person in the health care system who can initiate health-related behavioral changes. However, persisting prejudges may affect the physician-patient-relationship and therapy adherence. Interventions aimed at reducing stigmatizing attitudes should be implemented at an early stage of medical education.
\end{abstract}

Keywords: Alcoholism, medical students, stigmatization

\section{Die Bereitschaft von Medizinstudierenden zu Kürzungen der Gesundheitsausgaben für alkoholabhängige Personen}

Zusammenfassung: Hintergrund: Obwohl sie an einer schwerwiegenden Störung mit erhöhter Morbidität und Mortalität erkrankt sind, erleben alkoholabhängige Patienten häufig stigmatisierende Situationen im Gesundheitswesen. Ziel dieser Studie war es, Einstellungen von Medizinstudierenden zum Alkoholismus und ihre Bereitschaft zu Kürzungen der Gesundheitsausgaben bei alkoholabhängigen Personen zu untersuchen. Methoden:Insgesamt nahmen 2253 Studierende aller Bundesländer in Deutschland an der Studie teil. Mithilfe eines Online-Fragebogens wurden Einstellungen zum Alkoholismus, soziodemografische Variablen und Motive für die Wahl des Medizinstudiums erhoben. Die Bereitschaft der Studierenden zu Kürzungen der Gesundheitsausgaben bei alkoholabhängigen Personen wurde im Verhältnis zu anderen Krankheiten erfasst, darunter psychiatrische Erkrankungen (z. B. Depression, Schizophrenie), potentiell stigmatisierte nicht-psychiatrische Störungen (z. B. AIDS) und potentiell lebensstilbedingte akute (z.B. Herzinfarkt) oder chronische (z.B. Diabetes) medizinische Erkrankungen. Die Daten wurden mit hierarchischen logistischen Regressionsmodellen analysiert. Ergebnisse: Im Vergleich zu anderen medizinischen und psychischen Erkrankungen wurde Alkoholismus mit Abstand am häufigsten als Erkrankung mit einem finanziellem Einsparpotential gewählt. In multivariaten Analysen war die Präferenz zur Kosteneinsparung mit einem verstärkten Wunsch nach sozialer Distanz, hoher internaler Verantwortungszuschreibung, gering wahrgenommener Schwere und persönlicher Vulnerabilität, fehlender Erfahrung mit Alkoholismus im sozialen Umfeld der Probanden und bestimmten Motiven für die Wahl des Medizinstudiums assoziiert. Diskussion: Da die Mehrheit der Alkoholabhängigen keine suchtspezifische Hilfe in Anspruch nimmt, sind Ärzte in der Primärversorgung oftmals die einzigen Kontaktpersonen im Gesundheitssystem, die gesundheitsrelevante Verhaltensänderungen initiieren können. Persistierende Vorurteile können jedoch die Arzt-Patienten-Beziehung und Therapieadhärenz ungünstig beeinflussen. Interventionen zum Abbau stigmatisierender Einstellungen sollten in einem frühen Stadium der medizinischen Ausbildung implementiert werden.

Schlüsselwörter: Alkoholismus, Medizinstudenten, Stigmatisierung 
Alcohol dependence is one of the most prevalent mental disorders in Germany and associated with an increased risk for several health impairments, including liver damage, high blood pressure, heart disease, stroke or digestive problems (Lindenmeyer, 2016; Pabst, Kraus, Gomes de Matos \& Piontek, 2013). The World Health Organization (WHO, 2018 ) estimates that $5.3 \%$ of all deaths and $5.1 \%$ of all disability-adjusted years of life lost can be attributed to alcohol misuse. Aside from physical health impairments, alcohol dependence has a negative impact on psychological wellbeing, participation in social life and academic performance (Lindenmeyer, 2016; Marschall, Ullrich \& Sievers, 2009).

Despite being affected by a high-prevalent and severe disease, alcohol-dependent individuals often experience social discrimination in their daily life, e.g. problems in finding a job or renting a room (Fortney, Mukherjee, Curran, Fortney, Han \& Booth, 2004; Keyes et al., 2010). Furthermore, they are at risk to experience structural discrimination and being denied the necessary care because of their diagnosis (Schomerus, Matschinger, and Angermeyer; 2006). One important option of measuring structural discrimination is the distribution of financial means within the health care system (Beck, Dietrich, Matschinger \& Angermeyer, 2003; Schomerus, Matschinger \& Angermeyer, 2006). Compared to other medical and mental diseases, previous general population studies found that the readiness for cutbacks in health care expenditures for alcoholdependent individuals is increased when directly compared to individuals with other somatic and mental diseases (Beck et al., 2003; Schomerus, Matschinger \& Angermeyer, 2006). Due to the increasing costs for patient care and the limitation of the overall financial resources in the health system, the readiness for structural discrimination of certain patient groups may affect politicians' debate on the allocation of financial resources (Koch, 2005).

In general, the anticipation of discrimination and the fear of being labeled as an "alcoholic" might be one important barrier to help-seeking (Keyes et al., 2010). Among German alcohol-dependent individuals, Kraus, Piontek, PfeifferGerschel, \& Rehm (2015) found that $35.0 \%$ were registered in the health care system, $16 \%$ were utilizing specialized addiction services, and $1.8 \%$ were in rehabilitation treatment. Despite avoiding addiction-specific professional help, the majority had contact with the medical health system (Kraus, Piontek, Pfeiffer-Gerschel \& Rehm, 2015). Given that physicians in internal and general medicine are often the only professional contact person in the health care system, they are in a unique position to identify and provide interventions for people struggling with addiction. Thus, an appreciative and non-stigmatizing conversation is of importance to implement health-related behavioral changes or improve patients' commitment to seek addictive-specific help. Several studies found that the quality of the physician- patient relationship has a strong impact on therapy adherence, patient satisfaction, and the avoidance of litigation (Gilchrist et al., 2011; Levinson, Roter, Mullooly, Dull, \& Frankel, 1997). However, many physicians hold negative attitudes towards patients struggling with drugs or alcohol (Gilchrist et al., 2011; Mendiola, Galetto, \& Fingerhood, 2018). Previous research has shown that health care workers are at risk to experience burnout and increased stress levels when working with patients for which they hold negative attitudes (von Hippel, Brener \& von Hippel, 2008; Peltzer-Jones, 2011). To improve both patients' and physicians' satisfaction with the treatment, interventions aimed at reducing persistent stereotypes and negative attitudes towards alcoholism should already be implemented at an early stage of medical education. However, Jungbauer, Kamenik, Alfermann, \& Brähler (2004) found that only $37.9 \%$ of the German medical graduates felt well prepared for daily clinical practice and the contact with comorbid psychiatric patients after completing the 3rd state examination. In retrospect, the graduates reported blatant deficits in the teaching of practical skills and psychosocial competence (Jungbauer et al., 2004). In the past years, several reforms in medical studies focused on the intensified implementation of psychosocial aspects in the curriculum (Rheingans, Soulos, Mohr, Meyer, \& Guse, 2019). So far, however, little is known about current German medical students' attitudes towards alcoholism and its association with the readiness for structural discrimination. This study aimed to examine the following hypotheses:

a. German medical students' readiness for cutbacks in health care expenditures for alcohol-dependent individuals is increased compared to patients with other mental or somatic conditions.

b. Negative attitudes towards alcoholism and the absence of experiences with alcohol dependence in participants' social environment are associated with the preference for financial cutbacks in health care expenditures.

c. Humanistic motives for studying medicine are associated with the preference to avoid savings in health care expenditures of alcohol-dependent individuals.

\section{Methods}

\section{Study design}

An online questionnaire in German language was developed using the online platform umbuzoo.de. The participants were reached via the mailing lists of both the German Medical Students' Association and local medical student committees. Additionally, the questionnaire was distributed using the German Medical Students' Association's social 
media channel on Facebook. Medical students across all years were invited to participate in the study. To increase the number of participants, a reminder was sent after 7 and 14 days. The online questionnaire was active for three weeks between May and June 2018. As an incentive, the participants had the opportunity to win 1 of 10 Amazon vouchers with a total value of 100 Euro. In total, 2797 German medical students took part in the study. Of these, 2253 completed the online assessment and were included in the statistical analyses (drop-out rate: $19.5 \%$ ). A missing data analysis revealed that one-third of the participants who did not complete the online assessment canceled the completion of the questionnaire with the occurrence of the question of potential savings in the health care system. We did not find systematic drop-outs with regards to sociodemographic variables.

\section{Measures}

\section{Sample characteristics}

The assessed sociodemographic characteristics included gender, age, migration background, and current partnership. All sociodemographic characteristics were measured by single items.

\section{Preferences of the financial resource allocation within the health care system}

Based on previous studies (Angermeyer and Matschinger, 2003; Beck et al., 2003; Schomerus, Matschinger \& Angermeyer, 2006), the preferences of the financial resources allocation was measured in relation to the other cost-intensive and frequent diseases, including psychiatric conditions (e.g. depression, schizophrenia), chronic (e.g. rheumatism) and acute conditions (myocardial infarction), life-style related disorders (e.g. diabetes), and potentially stigmatized non-psychiatric disorders (e.g. AIDS). The participants were asked to choose three conditions they would prefer financial cutbacks in times of scarcity ("Imagine that expenses for medical care of patients with certain illnesses have to be reduced. Please name those three diseases where, in your opinion, cutbacks should be made.") Despite exaggerating the present health care situation in Germany, this question simulates a scenario when overt financial resource rationing is necessary and priorities have to be set (Schomerus, Matschinger \& Angermeyer, 2006).

\section{Attitudes towards individuals with alcoholism and own experiences with alcoholism}

The following five aspects dealing with attitudes and personal perceptions towards alcoholism were assessed: Severity ("How severely do you consider alcoholism to be?"), the estimated risk of suffering from alcoholism ("How high do you estimate the risk of developing alcoholism yourself?"), the perceived personal susceptibility ("In your opinion, how much does it depend on yourself to be affected by alcoholism?") as well as for the recovery ("In your opinion, how much does recovery from alcoholism depend on yourself ?"), and the wish for social distance ("If you had a room to rent, to what extent would you take someone with alcoholism as a lodger?"). All items could be answered on a 5-point Likert scale.

Furthermore, the participants were asked about their own experiences with alcoholism with the following two questions: "Have you ever suffered from alcoholism yourself?" and "Has someone of your immediate social environment ever suffered from alcoholism?".

\section{Individual motives for studying medicine}

Based on the study of Sönnichsen, Donner-Banzhoff, and Baum (2005), the participants were asked to rate the following possible motives for studying medicine on a 5-point Likert scale, ranging from "do not agree at all" to "totally agree": Career prospects, naturopathic work, sophisticated work, freelance work, secure workplace, working with people, social prestige, compatibility with family life, intellectual work, prospects for earnings, helping other people, and scientific work. A principal component analysis was performed for all items (Bartlett's test of sphericity $\chi^{2}(66)=5000.654$, $p<.001$; Kaiser-Meyer Olkin test $=0.682$ ). A four-component solution accounted for $58.29 \%$ of the variance. The first factor ("career orientated") included career prospects, sophisticated work, secure workplace, social prestige, intellectual work, and prospects for earnings. The second factor ("humanistic reasons") was consisted of working with people and helping other people. The third factor ("compatibility with social life") included compatibility with family life and the last factor ("independent work") included naturopathic work, freelance work, and scientific work.

\section{Ethics}

The study procedure was carried out according to the Declaration of Helsinki and was approved by the ethics committee of the University of Lübeck. All participants were informed about the purpose of the study and all provided informed consent. The data collection was anonymized. No conclusions could be drawn about individual persons.

\section{Statistical Analysis}

Univariate analyses were performed using chi-square tests and Mann-Whitney- $u$ tests. If the conditions for chi-square tests were not fulfilled, Fisher's exact tests were calculat- 
Table 1. Sample Characteristics ( $N=2253)$

\begin{tabular}{|c|c|c|c|c|}
\hline Sociodemographic variables & $\begin{array}{l}\text { Total } \\
(n=2253) n(\%)\end{array}$ & $\begin{array}{l}\text { Rather cut costs } \\
(n=1759) n(\%)\end{array}$ & $\begin{array}{l}\text { Rather avoid savings } \\
(n=494) n(\%)\end{array}$ & $p$ \\
\hline \multicolumn{5}{|l|}{ Gender ${ }^{1}$} \\
\hline Male & $555(24.7)$ & $425(24.2)$ & $130(26.4)$ & .304 \\
\hline Female & $1696(75.3)$ & $1334(75.8)$ & $362(73.6)$ & \\
\hline \multicolumn{5}{|l|}{ Age } \\
\hline$<25$ & $1601(71.1)$ & $1276(72.5)$ & $325(65.8)$ & .006 \\
\hline $25-30$ & $490(21.7)$ & $369(21.0)$ & $121(24.5)$ & \\
\hline$>30$ & $162(7.2)$ & $114(6.5)$ & $48(9.7)$ & \\
\hline \multicolumn{5}{|l|}{ Migration } \\
\hline $\begin{array}{l}\text { Migration background } \\
\text { No Migration background }\end{array}$ & $\begin{array}{r}353(15.7) \\
1900(84.3)\end{array}$ & $\begin{array}{r}272(15.5) \\
1487(84.5)\end{array}$ & $\begin{array}{r}81(16.4) \\
413(83.6)\end{array}$ & .614 \\
\hline \multicolumn{5}{|l|}{ Marital status } \\
\hline Single & $2078(92.2)$ & $1618(92.0)$ & $460(93.1)$ & .406 \\
\hline Partnership/Married & $175(7.8)$ & $141(8.0)$ & $34(6.9)$ & \\
\hline \multicolumn{5}{|l|}{ Location of the university } \\
\hline Baden-Württemberg & $230(10.2)$ & $163(9.2)$ & $67(13.6)$ & .009 \\
\hline Bayern & $360(16)$ & $293(16.7)$ & $67(13.6)$ & \\
\hline Berlin & $89(3.9)$ & $70(3.9)$ & $19(3.8)$ & \\
\hline Hamburg & $75(3.3)$ & $59(3.4)$ & $16(3.2)$ & \\
\hline Hessen & $138(6.1)$ & $117(6.7)$ & $21(4.3)$ & \\
\hline Mecklenburg-Vorpommern & $24(1.1)$ & $18(1.0)$ & $6(1.2)$ & \\
\hline Niedersachsen & $140(6.3)$ & $101(5.7)$ & $39(7.9)$ & \\
\hline Nordrhein-Westfalen & $342(15.1)$ & $274(15.5)$ & $68(13.7)$ & \\
\hline Rheinland-Pfalz & $55(2.4)$ & $42(2.4)$ & $13(2.6)$ & \\
\hline Saarland & $71(3.2)$ & $59(3.3)$ & $12(2.4)$ & \\
\hline Sachsen & $131(5.8)$ & $94(5.3)$ & $37(7.5)$ & \\
\hline Sachsen-Anhalt & $128(5.7)$ & $106(6.0)$ & $22(4.5)$ & \\
\hline Schleswig-Holstein & $398(17.7)$ & $300(17.0)$ & $98(19.8)$ & \\
\hline Thüringen & $72(3.2)$ & $63(3.9)$ & $9(1.8)$ & \\
\hline
\end{tabular}

Notes. ${ }^{1} \mathrm{n}=2251$ due to two missings.

ed. Multivariate analyses with the preference of financial cuts in the treatment of "alcoholism" as the dependent variable were performed using hierarchical logistic regression models. To evaluate the overall quality of the regression models, $R^{2}$ was measured. The level $p £ .05$ was defined as statistically significant. All data analyses were performed using IBM SPSS Statistics 25 .

\section{Results}

\section{Sample Characteristics}

The final sample consisted of 2253 participants from across all 36 German medical faculties. Each German uni- versity was represented by at least $\mathrm{n}>5$ participants. Table 1 displays all assessed sociodemographic characteristics of the sample.

\section{Preference of financial cutbacks in the treatment of alcohol-dependent individuals}

Of the total sample, 1759 (78.1\%) participants selected alcoholism as one of three diseases for which medical care expenditures could be spared. Compared to the other assessed conditions, alcoholism was by far the most frequently chosen disease where cost savings could be made ( $p=.001$, not shown in the table). The second most frequently chosen disease was rheumatism $(39.5 \%)$, followed by diabetes (39\%), Alzheimer's (28.2\%), schizo- 
Table 2. Attitudes towards alcoholism

\begin{tabular}{|c|c|c|c|}
\hline Item & $\begin{array}{l}\text { Rather cut costs } \\
(n=1759) \\
\text { Mean Ranks }\end{array}$ & $\begin{array}{l}\text { Rather avoid savings } \\
(n=494) \\
\text { Mean Ranks }\end{array}$ & $p$ \\
\hline "How severely do you consider alcoholism to be?"” & 1045.90 & 1415.78 & $<.001$ \\
\hline "How high do you estimate the risk of developing alcoholism yourself?"1 & 1095.95 & 1237.56 & $<.001$ \\
\hline "In your opinion, how much does it depend on yourself to be affected by alcoholism?"” & 1203.48 & 854.67 & $<.001$ \\
\hline "In your opinion, how much does recovery from alcoholism depend on yourself?"1 & 1178.09 & 945.08 & $<.001$ \\
\hline "If you had a room to rent, to what extent would you take someone with alcoholism as a lodger?"1 & 1089.20 & 1261.58 & $<.001$ \\
\hline "Have you ever suffered from alcoholism yourself?", n (\%)² & $4(0.2)$ & $4(0.8)$ & .075 \\
\hline "Has someone of your immediate social environment ever suffered from alcoholism?", n (\%)³ & $525(29.8)$ & $198(40.1)$ & $<.001$ \\
\hline
\end{tabular}

Notes. ${ }^{1} p$-values were derived from Mann-Whitney $u$ tests $;{ }^{2} p$-value was derived from Fisher's exact tests; ${ }^{3} p$-value was derived from chi-square tests.

phrenia (27.9\%), AIDS (27.3\%), depression (22.5\%) and heart attack (17.7\%). Cancer was the least chosen disease (11\%).

\section{Attitudes towards alcoholism and own experiences with alcoholism in participants' social environment}

Table 2 shows that individuals who chose alcoholism as a preference for financial cutbacks less likely consider alcoholism as a severe disease $(p<.001 ; \mathrm{r}=.247)$, anticipated a lower risk of being affected by alcoholism themselves $(p<.001 ; \mathrm{r}=.110)$, showed an increased internal attribution of becoming alcoholic $(p<.001 ; \mathrm{r}=.238)$ and for being responsible for the recovery $(p<.001 ; \mathrm{r}=.173)$, and reported an increased wish for social distance towards alcohol-dependent individuals $(p<.001 ; \mathrm{r}=.117)$ compared to individuals who prefer financial cutbacks of other conditions. In addition, they had less contact with alcoholism in their social environment $(p<.001 ; \varphi=.091)$.

\section{Reasons for studying medicine}

In a hierarchical logistic regression analysis, we tested the association of the preference of financial cutbacks in the health care expenditures for alcohol-dependent individuals with the assessed attitudes towards alcoholism, participants' motives for studying medicine, own experiences with alcoholism in participants' social environment and sociodemographic variables. The multicollinearity of independent variables was tested by the variance inflation factor coefficients and was found to be not problematic. Table 3 shows that the assessed attitudes towards alcohol- ism except for the wish for social distance, own experiences with alcoholism in participants' social environment, and humanistic motives for studying medicine were associated with the preference of financial cutbacks in the treatment of alcohol dependence. Sociodemographic variables had no separate contribution.

\section{Discussion}

This study aimed to investigate German medical students' attitudes towards alcoholism and its interrelation with preferences of the financial resources allocation in the health care system. Within the context of other cost-intensive and frequent diseases, we found that the financial means for the care of alcoholism had by far the lowest priority. Furthermore, the preference for financial cutbacks was associated with several negative attitudes towards alcoholism, the absence of own experiences with alcoholism in participants' social environment, and humanistic motives for studying medicine.

Supporting our first hypothesis, we found that German medical students most likely prefer financial cutbacks in health care expenditures for alcohol-dependent individuals when directly compared to other common and costintensive diseases. This is in line with the findings of previous studies (Hanson, 1998; Beck et al., 2003; Schomerus, Matschinger \& Angermeyer, 2006). However, in a German general population study (Schomerus, Matschinger \& Angermeyer, 2006) found that all three assessed psychiatric conditions (alcoholism, depression, and schizophrenia) were by far the most stigmatized diseases. This could not be replicated in our sample. Since schizophrenia and depression were categorized in fifth and sev- 
Table 3. Multivariate logistic regression analysis

\begin{tabular}{|c|c|c|c|c|c|c|c|c|c|}
\hline & \multicolumn{3}{|c|}{ Model 1} & \multicolumn{3}{|c|}{ Model 2} & \multicolumn{3}{|c|}{ Model 3} \\
\hline & OR & $95 \% \mathrm{Cl}$ & $p$ & OR & $95 \% \mathrm{Cl}$ & $p$ & OR & $95 \% \mathrm{Cl}$ & $p$ \\
\hline \multicolumn{10}{|l|}{$\begin{array}{l}\text { Attitudes towards alcohol } \\
\text { dependence }\end{array}$} \\
\hline Perceived severity & 0.57 & $0.50-0.65$ & $<.001$ & 0.56 & $0.49-0.64$ & $<.001$ & 0.57 & $0.50-0.64$ & $<.001$ \\
\hline $\begin{array}{l}\text { Perceived personal } \\
\text { vulerability }\end{array}$ & 0.80 & $0.70-0.91$ & .001 & 0.81 & $0.71-0.92$ & .002 & 0.84 & $0.73-0.96$ & .010 \\
\hline $\begin{array}{l}\text { Perceived responsibility to suffer } \\
\text { from alcohol dependence }\end{array}$ & 1.34 & $1.34-1.73$ & $<.001$ & 1.50 & $1.32-1.71$ & $<.001$ & 1.50 & $1.32-1.71$ & $<.001$ \\
\hline Perceived responsibility of recovery & 1.09 & $1.08-1.46$ & .002 & 1.24 & $1.07-1.44$ & .004 & 1.24 & $1.07-1.45$ & .004 \\
\hline $\begin{array}{l}\text { Wish for social distance towards } \\
\text { alcohol-dependent individuals }\end{array}$ & 1.12 & $0.99-1.26$ & .052 & 1.12 & $0.99-1.26$ & .052 & 1.12 & $0.99-1.26$ & .063 \\
\hline \multicolumn{10}{|l|}{ Motives for studying medicine } \\
\hline Career orientated & & & & 1.02 & $0.99-1.05$ & .068 & 1.02 & $0.99-1.05$ & .064 \\
\hline Humanistic reasons & & & & 1.09 & $1.02-1.72$ & .008 & 1.08 & $1.01-1.16$ & .017 \\
\hline Compatibility with social life & & & & 1.01 & $0.92-1.12$ & .722 & 1.01 & $0.91-1.11$ & .846 \\
\hline Independent work & & & & 1.02 & $0.97-1.07$ & .286 & 1.02 & $0.97-1.07$ & .298 \\
\hline \multicolumn{10}{|l|}{ Experiences with alcoholism } \\
\hline $\begin{array}{l}\text { Alcoholism in participants' } \\
\text { social environment }\end{array}$ & & & & & & & 0.76 & $0.60-0.95$ & .017 \\
\hline \multicolumn{10}{|l|}{ Sociodemographic variables } \\
\hline Female gender ${ }^{1}$ & & & & & & & 1.17 & $0.90-1.50$ & .225 \\
\hline \multicolumn{10}{|l|}{$\mathrm{Age}^{2}$} \\
\hline$\leq 25$ & & & & & & & 1.40 & $0.94-2.07$ & .090 \\
\hline $25-30$ & & & & & & & 1.34 & $0.87-2.06$ & .173 \\
\hline
\end{tabular}

Notes. ${ }^{1} n=2251$ due to two ambigious answers in the assessment of gender. ${ }^{2}$ Reference category: $>30$ years. Model 1: Nagelkerkes $R^{2}=.160 ;$ Model $2=$ Nagelkerkes $\mathrm{R}^{2}=.170$, Model $3=$ Nagelkerkes $\mathrm{R}^{2}=.177$.

enth places, these findings may indicate that German medical students do not prefer financial cutbacks in health care expenditures of mental diseases per se, but especially in the treatment of alcohol-dependent individuals.

Furthermore, we found that several negative attitudes towards alcoholism were associated with a preference for financial cutbacks in health care expenditures of alcoholism. This is in line with previous general population studies demonstrating the persistence of widespread negative attitudes towards alcohol-dependent individuals (Schomerus, Matschinger, \& Angermeyer, 2014). Medical students' prejudices against certain patient groups may be related to their subsequent similar views as physicians and thus determine the quality of therapy for those affected (von Hippel, Brener \& von Hippel, 2008; PeltzerJones, 2011). This, in turn, may have a strong negative impact on patients' self-confidence in remaining abstinent in the future (Corrigan, Watson, \& Barr, 2006; Schomerus, Corrigan, Klauer, Kuwert, Freyberger \& Lucht, 2011).

Finally, the link between participants' own experiences with alcoholism and the preference for cutbacks was assessed. In line with previous studies (e.g. Keyes et al., 2010), we found that the readiness for stigmatization was lower if there is or has been an alcohol addiction in the immediate social environment. These findings indicate that contact with this group of patients does not promote a rejective attitude but rather seems to reduce barriers and prejudices. In contrast to our expectations, we found that individuals who stated humanistic reasons for studying medicine most likely chose to cut costs in the treatment of alcoholism. Perhaps this finding can be explained mediating third variables that were not considered in our regres- 
sion model and could thus be investigated in future studies. Concerning sociodemographic variables, we did not find differences between gender and age groups in the multivariate model.

Summing up, our findings indicate that the severity of alcohol dependence is widely neglected among German medical students when it comes to the preservation of financial resources in times of scarcity. Stigmatization of certain patient groups may isolate those affected and undermine the provision of effective help in internal medical care (Fortney et al., 2004). Instead of facilitating change, stigma can aggravate problematic behavior patterns and impede the efficacy of the treatment (Fortney et al., 2004). These findings highlight the importance of intensified interventions aimed at reducing persistent prejudices and improving communication competencies in the curriculum of future physicians. Aside from the ethical implications of a majority of German medical students seem to have low regard for a significant percentage of their future patient population, there are practical implications as well. Previous research has shown that individuals working in health care are more likely to experience increased stress levels when working with patients for which they hold negative attitudes (PeltzerJones, 2011). This, in turn, was correlated with a higher intention to change jobs (von Hippel, Brener \& von Hippel, 2008). To improve both patients' and physicians' satisfaction with the treatment, medical students should be encouraged to reflect their attitudes and illness beliefs towards mental disorders. A central strategy to combat stigma in the health care system is education and the correction of false stereotypes. This stigma-reducing effect of personal contact with affected individuals in lectures has been documented for other psychiatric diseases (Angermeyer \& Dietrich, 2006; Yamaguchi et al., 2013). Since medical students will have a multiplier function in the future, anti-stigma interventions concerning psychiatric diseases are of particular importance. However, since we found that not individuals with psychiatric diseases per se but in particular alcohol-dependent individuals seem to be at risk for structural discrimination, an approach aimed reducing the stigma of 'psychiatric illness' in general may miss the specific personal perceptions of each of the disorders and thus might be ineffective (Angermeyer \& Matschinger, 2003). Medical students should at an early stage of education learn what patients struggling with addiction need: Not exclusion and rejection, but rather appreciation to promote motivation for health-behavioral changes or seeking professional addiction-specific help (Schomerus et al., 2017; Schomerus \& Rumpf, 2017).

\section{Limitations and strengths}

These findings should be interpreted with caution due to several limitations of this study. In the assessment of the financial allocation preferences in the health care system, there was no possibility to choose the option "undecided" or "financial resources should not be reduced for any disease". Furthermore, the focus on nine diseases cannot represent the entire spectrum of the health care system. Since participation in this study was voluntary and the sample was thus self-selected, this might have had an impact on the representativeness of our findings. Finally, less stigmatizing terms such as alcohol use disorder instead of "alcoholism" might have been more appropriate. Despite these limitations and to the best of our knowledge, this is the first study investigating German medical students' readiness for structural discrimination of alcohol-dependent individuals and related attitudes towards alcoholism. Using an online questionnaire has certain advantages compared to face-to-face or telephone-based interviews: A large distribution of the questionnaire can easily be realized and reflect a broad spectrum of German medical students by ruling out several potential interviewer biases. The drop-out rate with $19.5 \%$ can be considered as good.

\section{Conclusion}

Despite being affected by one of the most prevalent and serious mental disorders, alcohol-dependent individuals are at risk to face social and structural discrimination within the health care system. Compared to other common and cost-intensive diseases, we found that German medical students' readiness for financial cutbacks in health care care expenditures for alcohol-dependent individuals is considerably increased. Furthermore, the preference for financial cutbacks is associated with several negative attitudes towards alcoholism, the absence of own experiences with alcoholism in participants' social environment, and humanistic motives for studying medicine. Since the treatment adherence is moderated by the quality of the patient-physician relationship and the extent to which both build a shared understanding of illness and treatment, these findings highlight the importance of implementing interventions aimed at reducing persisting stereotypes of alcohol-dependent individuals already at an early stage of medical education. 


\section{References}

Angermeyer, M.C. \& Matschinger, H. (2003). The stigma of mental illness effects of labelling on public attitudes towards people with mental disorders. Acta Psychiatrica Scandinavica, 108 (4), 304-309.

Angermeyer, M.C. \& Dietrich, S. (2006). Public beliefs about and attitudes toward people with mental illness: A review of population studies. Acta Psychiatrica Scandinavica, 113 (3), 163-179.

Beck, M., Dietrich, S., Matschinger, H. \& Angermeyer, M.C. (2003). Alcoholism: Low standing with the public? Attitudes towards spending financial resources on medical care and research on alcoholism. Alcohol and Alcoholism, 38 (6), 602-605.

Corrigan, P.W., Watson, A.C. \& Barr, L. (2006). The self-stigma of mental illness. Implications for self-esteem and self-efficacy. Journal of Social and Clinical Psychology, 25 (9), 875-884.

Fortney, J., Mukherjee, S., Curran, G., Fortney, S., Han, X.T. \& Booth, B. M. (2004). Factors associated with perceived stigma for alcohol use and treatment among at-risk drinkers. Journal of Behavioral Health Services \& Research, 31 (4), 418-429.

Gilchrist, G., Moskalewicz, J. Slezakova, S., Okruhlica, L. Torrens, M., Vajd, R. \& Baldacchino, A. (2011). Staff regard towards working with substance users: a European multi-centre study. Addiction, 106 (6), 1114-1125.

Hanson, K.W. (1998). Public opinion and the mental health parity debate: lessons from the survey literature. Psychiatric Service, 49 (8),1059-1066.

Jungbauer, J., Kamenik, C., Alfermann, D. \& Brähler, E. (2004). Wie bewerten angehende Ärzte rückblickend ihr Medizinstudium? Ergebnisse einer Absolventenbefragung. Gesundheitswesen, 66 (1), 51-56.

Keyes, K.M., Hatzenbuehler, M.L., McLaughlin, K. A., Link, B., Olfson, M., Grant, B. F. \& Hasin, F. (2010). Stigma and treatment for alcohol disorders in the United States. American Journal of Epidemiology, 172 (12), 1364-1372.

Koch, K. (2005). Rationierungen im Gesundheitswesen: Forderung nach offener Diskussion [Rationing within the health care system: demand for an open debate]. Deutsches Ärzteblatt, 102 (15), 1036-1038.

Kraus, L., Piontek, D., Pfeiffer-Gerschel, T. \& Rehm, J. (2015). Inanspruchnahme gesundheitlicher Versorgung durch Alkoholabhängige. Suchttherapie, 16 (1), 18-26.

Levinson, W., Roter, D.L., Mullooly, J.P., Dull, V.T. \& Frankel, R.M. (1997). Physician-patient communication-The relationship with malpractice claims among primary care physicians and surgeons. Jama-Journal of the American Medical Association, 277 (7), 553-559.

Lindenmeyer, J. (2016). Alkoholabhängigkeit. Göttingen: Hogrefe.

Marschall, U., Ullrich, W. \& Sievers, C. (2009). Eine Sucht kommt selten allein - Sucht, Komorbidität und psychotherapeutische Behandlung. In U. Repschläger (Hrsg.). Barmer Gesundheitswesen aktuell 2009(S. 252-277). Wuppertal: Barmer Ersatzkasse.

Mendiola, C. K., Galetto, G. \& Fingerhood, M. (2018). An Exploration of Emergency Physicians' Attitudes toward Patients with Substance Use Disorder, Journal of Addiction Medicine, 12 (2), 132-135.

Pabst, A., Kraus, L., Gomes de Matos, E. \& Piontek, D. (2013). Substanzkonsum und substanzbezogene Störungen in Deutschland im Jahr 2012. Sucht, 59 (6), 321-331.

Peltzer-Jones, J. (2011). Survey: ED physicians report burnout, desire help for dealing with frequent users. ED Management, 23 (9), 104-105.

Rheingans, A., Soulos, A., Mohr, S., Meyer, J. \& Guse, A. H. (2019). The Hamburg integrated medical degree program iMED. GMS Journal for Medical Education, 36 (5), doi: 10.3205/zma001260.

Schomerus, G., Matschinger, H. \& Angermeyer, M.C. (2006). Preferences of the public regarding cutbacks in expenditure for patient care: Are there indications of discrimination against those with mental disorders? Social Psychiatry and Psychiatric Epidemiology, 41 (5), 369-377.

Schomerus, G., Corrigan, P.W., Klauer, T., Kuwert, P., Freyberger, H.J. \& Lucht, M. (2011). Self-stigma in alcohol dependence: Consequences for drinking-refusal self-efficacy. Drug and Alcohol Dependence, 114 (1), 12-17.

Schomerus, G., Matschinger, H. \& Angermeyer, M.C. (2014). Attitudes towards alcohol dependence and affected individuals: persistence of negative stereotypes and illness beliefs between 1990 and 2011. European Addiction Research, 20 (6), 293-299.

Schomerus, G., Bauch, A., Elger, B., Evans-Lacko, S., Frischknecht, U., Klingemann, H., Kraus, L., Kostrzewa, R., Rheinlander, J., Rummel, C., Schneider, W., Speerforck, S., Stolzenburg, S., Sylvester, E., Tremmel, M., Vogt, I., Williamson, L., Heberlein, A., Rumpf, H.J. \& Zusammenarbeit Deutsch Gesellschaft (2017). Understanding and overcoming the stigma of substance use disorders. Sucht, 63 (5), 253-259.

Schomerus, G. \& Rumpf, H.J. (2017). The stigma of substance use disorders needs to be overcome. Sucht, 63 (5), 251-252.

Sönnichsen, A.C., Donner-Banzhoff, N. \& Baum, E. (2005). Motive, Berufsziele und Hoffnungen von Studienanfängern im Fach Medizin. Zeitschrift für Allgemeinmedizin, 81 (5), 222-225.

von Hippel, W., Brener, L. \& von Hippel, C. (2008). Implicit prejudice toward injecting drug users predicts intentions to change jobs among drug and alcohol nurses. Psychological Science, 19 (1), $7-11$.

World Health Organization (2018). Global status report on alcohol and health. Geneva: World Health Organization.

Yamaguchi, S., Wu, S. I., Biswas, M., Yate, M., Aoki, Y., Barley, E. A. \& Thornicroft, G. (2013). Effects of short-term interventions to reduce mental health-related stigma in university or college students: a systematic review. Journal of Nervous and Mental Disease, 201(6): 490-503.

\section{Funding sources}

No funding sources.

\section{Acknowledgment}

We would like to thank all students and universities for participating in our study.

\section{Authors' contribution}

$\mathrm{HH}$ : statistical analysis and interpretation of the findings, preparation of the manuscript draft. JK: study concept and design, data gathering, revision of the manuscript. GS: revision of the manuscript. GB, H-JR: obtained study concept and design, statistical analysis and interpretation of findings, revision of the manuscript. All authors had full access to all data in the study and take responsibility for the integrity of the data and the accuracy of the data analysis.

\section{Declaration of concurring interests}

The authors declare that they have no conflict of interest.

\section{Historie}

Manuscript submitted: February 1, 2020

Manuscript accepted: March 10, 2020

\section{Hannah Hoffmann}

Department of Psychiatry and Psychotherapy

University of Lübeck

Ratzeburger Allee 160

23538 Lübeck

Germany

hannah.hoffmann@uksh.de 